\title{
Triggering of the Ventilator in Patient-Ventilator Interactions
}

\author{
Catherine SH Sassoon MD
}

\author{
Introduction \\ Influence of Ventilator Factors on Patient Effort or Work of Breathing \\ Triggering Phase \\ Post-Triggering Phase \\ Ventilator Factors as Determinants of Patient-Ventilator Interaction \\ Triggering Phase \\ Post-Triggering Phase \\ Ventilator Modes for Improving Patient-Ventilator Interaction \\ Proposed Algorithm to Improve Patient-Ventilator Synchrony
}

\begin{abstract}
With current ventilator triggering design, in initiating ventilator breaths patient effort is only a small fraction of the total effort expended to overcome the inspiratory load. Similarly, advances in ventilator pressure or flow delivery and inspiratory flow termination improve patient effort or inspiratory muscle work during mechanical ventilation. Yet refinements in ventilator design do not necessarily allow optimal patient-ventilator interactions, as the clinician is key in managing patient factors and selecting appropriate ventilator factors to maintain patient-ventilator synchrony. In patient-ventilator interactions, unmatched patient flow demand by ventilator flow delivery results in flow asynchrony, whereas mismatches between mechanical inspiratory time (mechanical $\mathrm{T}_{\mathrm{I}}$ ) and neural $T_{I}$ produce timing asynchrony. Wasted efforts are an example of timing asynchrony. In the triggering phase, trigger thresholds that are set too high or the type of triggering methods induces wasted efforts. Wasted efforts can be aggravated by respiratory muscle weakness or other conditions that reduce respiratory drive. In the post-triggering phase, ventilator factors play an important role in patient-ventilator interaction; this role includes the assistance level, set inspiratory flow rate, $T_{I}$, pressurization rate, and cycling-off threshold, and to some extent, applied PEEP. This paper proposes an algorithm that clinicians can use to adjust ventilator settings with the goal to eliminate or reduce patients' wasted efforts. Key words: mechanical ventilation; positive-pressure ventilation; pressure-control ventilation; patient-ventilator interaction; ventilator triggering; work of breathing; time constant. [Respir Care 2011;56(1):39-48. (C) 2011 Daedalus Enterprises]
\end{abstract}

\section{Introduction}

Nearly a quarter of a century ago, flow triggering was incorporated in intensive care unit (ICU) microprocessor-

Catherine S Sassoon MD is affiliated with the Division of Pulmonary and Critical Care Medicine, Department of Medicine, Veterans Affairs Long Beach Healthcare System, Long Beach, California.

The author has disclosed no conflicts of interest.

This work was supported by the Department of Veterans Affairs Medical Research Service based ventilators with the goal to reduce patient triggering effort. ${ }^{1,2}$ Ventilator triggering designs have evolved such that the proportion of patient effort required to trigger the ventilator is only a small fraction of the total effort expended to

\footnotetext{
Dr Sassoon presented a version of this paper at the 46th RESPIRATORY CARE Journal Conference, "Patient-Ventilator Interaction," held March 1921, 2010, in Cancún, Quintana Roo, Mexico.
}

Correspondence: Catherine S Sassoon MD, Pulmonary and Critical Care Section, Veterans Affairs Long Beach Healthcare System, 5901 East 7th Street, 11/111P, Long Beach CA 90822. E-mail: csassoon@uci.edu. 


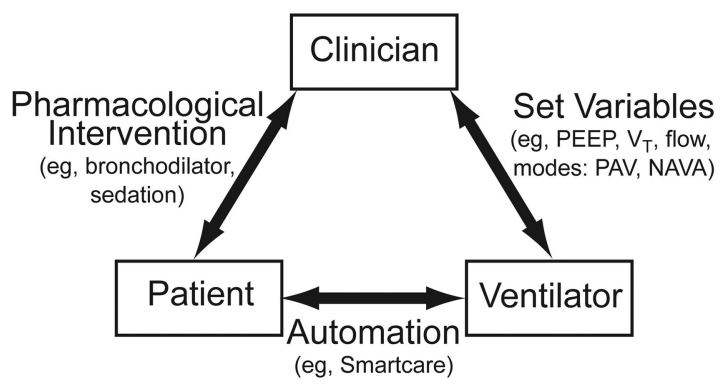

Fig. 1. Interactions among clinician, patient, and ventilator. The clinician is key in the interaction. The clinician can improve patientventilator interaction, for instance, by administering a bronchodilator to decrease intrinsic PEEP, or by applying appropriate ventilator settings (eg, applied PEEP, $\mathrm{V}_{\mathrm{T}}$, flow) or specific ventilatory modes (eg, proportional assist ventilation [PAV], or neurally adjusted ventilatory assist [NAVA]). On the other hand, the clinician can worsen the interaction, for example, by administering heavy sedation. A bidirectional interaction between patient and ventilator occurs with automation (eg, with SmartCare, a pressure-support mode that uses artificial intelligence for weaning).

overcome inspiratory muscle load. ${ }^{3}$ Recently, another ventilator triggering method, called shape-signal triggering, was introduced to further minimize patient-triggered effort. ${ }^{3}$ However, despite refinements in ventilator triggering design, any mismatch between the patient's triggering of the ventilator and the clinician-set ventilator settings will induce patientventilator asynchrony that remains problematic in ventilator management. ${ }^{4}$ Significant patient-ventilator asynchrony (using a threshold value of $10 \%$ or greater of breaths being asynchronous) is relatively common, occurring in approximately $25 \%$ of patients receiving conventional patient-triggered mechanical ventilation, and is associated with prolonged duration of mechanical ventilation. ${ }^{4,5}$ Of note, some degree of patient-ventilator asynchrony is ubiquitous.

Important determinants of patient-ventilator asynchrony include both patient and ventilator factors; however, the clinician's input cannot be overemphasized (Fig. 1). The clinician can either improve or worsen the interactions. For instance, reducing the pressure-support level when it has been set too high ${ }^{6}$ or administering a high sedation level ${ }^{7}$ can improve or worsen patient-ventilator asynchrony, respectively. Thus, the clinician is key in optimizing patient-ventilator interactions, and must understand the underlying pathophysiology or determinants and types of patient-ventilator asynchrony. This fundamental knowledge is important to take steps in improving patient-ventilator interaction. A patient-ventilator interaction without clinician input is essentially an automation (eg, SmartCare, Dräger Medical, Lübeck, Germany), a pressure-support mode that uses artificial intelligence for weaning. ${ }^{8,9}$

This paper will review the influence of ventilator factors on patient effort or inspiratory muscle work in the triggering and post-triggering phase, determinants of patient-ventilator interaction, and the impact of controlling ventilator factors on patient-ventilator interaction, and present a pro-

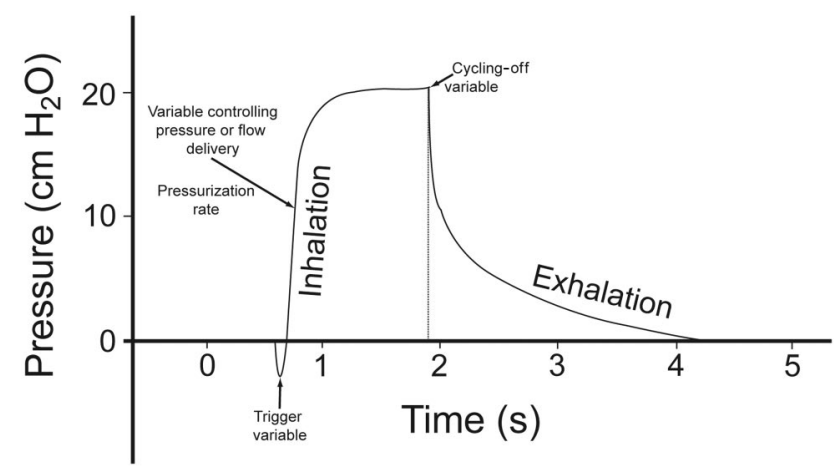

Fig. 2. Components of a patient-triggered mechanical breath. The triggering phase comprises the trigger variable. The post-triggering phase consists of the variable controlling pressure or flow delivery and the cycling-off variable. In pressure-control ventilation, the pressurization rate determines flow delivery, while in flowcycled pressure-control ventilation the cycling-off variable determines mechanical inspiratory time.

posed algorithm to improve patient-ventilator interaction in patients receiving conventional mechanical ventilation.

\section{Influence of Ventilator Factors on Patient Effort or Work of Breathing}

The triggering phase- that is, from onset of patient effort to onset of flow delivery-comprises the trigger variable of a mechanical breath. The post-triggering phasethat is, from onset of flow delivery to termination of inspiratory flow-constitutes the variables controlling pressure or flow delivery and the cycling-off variable, also known as the expiratory triggering variable (Fig. 2).

\section{Triggering Phase}

Trigger Variable. New designs have markedly improved ventilator performance. In bench testing of ICU ventilators released in 2000 or afterwards, in which the trigger variable was set to sufficient sensitivity but without auto-triggering, all but 3 ventilators tested had a triggering time delay of less than $60 \mathrm{~ms}$ (Fig. 3). ${ }^{10}$ In contrast, among those released prior to 2000 , only 2 ventilators had a triggering time delay of less than $60 \mathrm{~ms} .{ }^{11}$ Triggering time delay is the time from onset of triggering effort to onset of flow delivery. Patient effort to trigger, expressed as pressure-time product of the inspiratory muscles during triggering $\left(\mathrm{PTP}_{\text {trig }}\right)$, is relatively constant with increasing ventilatory support. ${ }^{3,12}$ A constant $\mathrm{PTP}_{\text {trig }}$ is caused by a decrease in the pressure-development rate when the subject triggers the ventilator, and a simultaneous increase in the triggering time delay when the ventilator support is increased (Table 1). In response to 3 levels of pressuresupport ventilation (PSV) - a baseline of $18 \mathrm{~cm} \mathrm{H}_{2} \mathrm{O}$, low, and high levels $\left(5 \mathrm{~cm} \mathrm{H}_{2} \mathrm{O}\right.$ less or greater than baseline, 


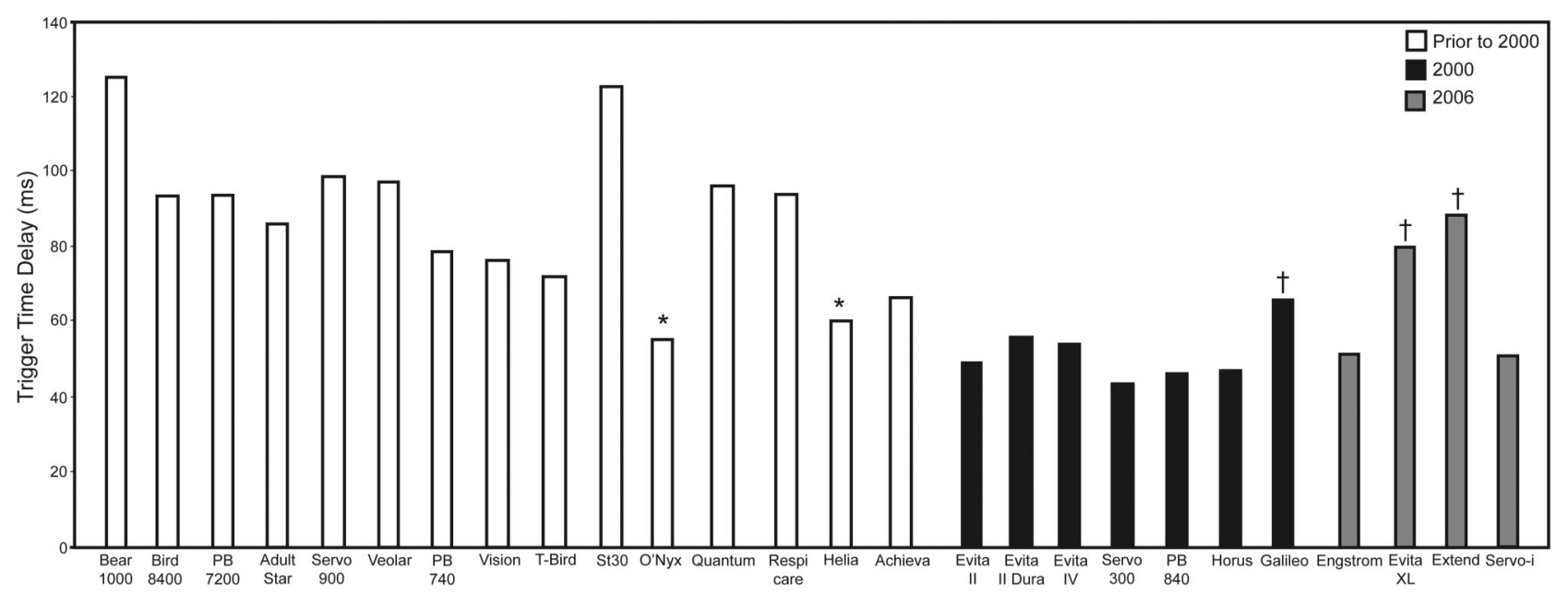

Fig. 3. Triggering time delay of various intensive care unit ventilators, based on bench testing. The white bars represent ventilators released prior to 2000. Only 2 ventilators $\left(^{*}\right)$ have a triggering time delay of less than $60 \mathrm{~ms}$. In contrast, among ventilators released after 2000 (black and dark gray bars), all but 3 ventilators $(\dagger)$ have a triggering time delay of less than 60 ms. (From data in References 10 and 11.)

Table 1. Triggered Pressure-Time Product of the Inspiratory Muscles as a Function of Pressure-Support Level in 12 Patients With Acute Respiratory Failure

\begin{tabular}{|c|c|c|c|}
\hline & \multicolumn{3}{|c|}{ Pressure-Support Level (mean $\pm \mathrm{SE})^{*}$} \\
\hline & Low & Baseline & High \\
\hline Triggering time delay (ms) & $158 \pm 18$ & $165 \pm 26$ & $206 \pm 45$ \\
\hline$\Delta \mathrm{P} / \Delta \mathrm{T}\left(\mathrm{cm} \mathrm{H} \mathrm{H}_{2} \mathrm{O} / \mathrm{s}\right)$ & $22.0 \pm 3.4$ & $18.2 \pm 2.8$ & $12.6 \pm 3.0 \dagger$ \\
\hline $\mathrm{PTP}_{\text {trig }}\left(\mathrm{cm} \mathrm{H}_{2} \mathrm{O} \cdot \mathrm{s}\right)$ & $0.4 \pm 0.1$ & $0.4 \pm 0.1$ & $0.3 \pm 0.1$ \\
\hline $\mathrm{PTP}_{\text {tot }}\left(\mathrm{cm} \mathrm{H}_{2} \mathrm{O} \cdot \mathrm{s}\right)$ & $9.5 \pm 1.7$ & $7.7 \pm 1.2$ & $4.8 \pm 1.0 \dagger$ \\
\hline Average $\mathrm{PTP}_{\text {trig }} / \mathrm{PTP}_{\text {tot }}(\%)$ & 4.2 & 5.2 & 6.3 \\
\hline \multicolumn{4}{|c|}{$\begin{array}{l}\text { * The mean } \pm \mathrm{SE} \text { baseline pressure support was } 17.6 \pm 0.8 \mathrm{~cm} \mathrm{H}_{2} \mathrm{O} \text {. The low and high } \\
\text { levels were } \pm 5 \mathrm{~cm} \mathrm{H}_{2} \mathrm{O} \text { from baseline. The ventilator was an Evita } 4 \text {. } \\
\dagger P<.05 \text {, compared to baseline and low pressure support. } \\
\Delta \mathrm{P} / \Delta \mathrm{T}=\text { rate of pressure development during triggering } \\
\mathrm{PTP}_{\text {trig }}=\text { pressure-time product of the inspiratory muscles during the triggering phase } \\
\mathrm{PTP}_{\text {tot }}=\text { total PTP during inspiration } \\
\text { (Adapted from Reference } 3 \text {.) }\end{array}$} \\
\hline
\end{tabular}

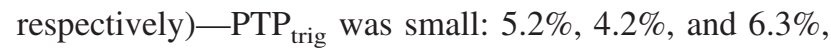
respectively, of the total inspiratory effort or total PTP of the inspiratory muscles $\left(\mathrm{PTP}_{\text {tot }}\right)^{3}$ (see Table 1$)$.

\section{Post-Triggering Phase}

Variable Controlling Pressure or Flow Delivery. For most ICU ventilators released since 2000, the performance of the pressurization rate for flow delivery in the PSV mode has been adequate, with only a few exceptions (eg, Avea, Viasys, Yorba Linda, California; and Centiva, GE Healthcare, Madison, Wisconsin). ${ }^{10}$ However, increasing the pressure-support level improves performance. ${ }^{10}$

With PSV, setting the pressurization rate allows alteration of the initial pressure ramp and the initial peak flow rate. Increasing the pressurization rate is associated with a reduced time to reach the pressure-support level and with an increased peak flow rate. The effects of the pressurization rate on inspiratory muscle work, expressed as work rate (Joules/min) and the sensation of dyspnea were studied in patients with acute lung injury, employing a 5 or $15 \mathrm{~cm} \mathrm{H}_{2} \mathrm{O}$ pressure-support level. ${ }^{13}$ The pressurization rate - an arbitrary dimensionless scale of -9 (lowest) to +9 (highest) — was varied at 5 levels: a baseline or default level and 2 below and 2 above it. Overall work rate was lower with a high PS level. With either a low or a high PS level, the highest level of work rate was achieved at the lowest pressurization rate (Fig. 4). ${ }^{13}$ Compared with the baseline pressurization rate, the highest setting did not further reduce work rate.

The effect of pressurization rate on the perception of dyspnea, measured using the Borg perceived dyspnea scale, ranged from 0 to $10 \mathrm{~cm}$, with $0 \mathrm{~cm}$ as no shortness of breath and $10 \mathrm{~cm}$ as extremely severe shortness of breath. As shown in Figure 4, the perception of dyspnea followed a U-shape pattern, with the worst dyspnea at the lowest and highest pressurization rates. ${ }^{13}$ At the lowest pressurization rate the sensation of dyspnea was perceived as "air hunger," with the afferent signal arising from the chest. At the highest pressurization rate, the sensation of dyspnea was perceived as "airway discomfort," with the afferent signal originating from the upper airways. ${ }^{14}$ Thus, in acute lung injury, increasing the pressurization rate or delivered flow rate above what is sufficient to meet patient flow demand does not provide further benefit in unloading inspiratory muscle work, and in fact, induces breathing discomfort.

Cycling-Off Variable. Effects of varying the cycling-off variable on inspiratory muscle work are determined by the 

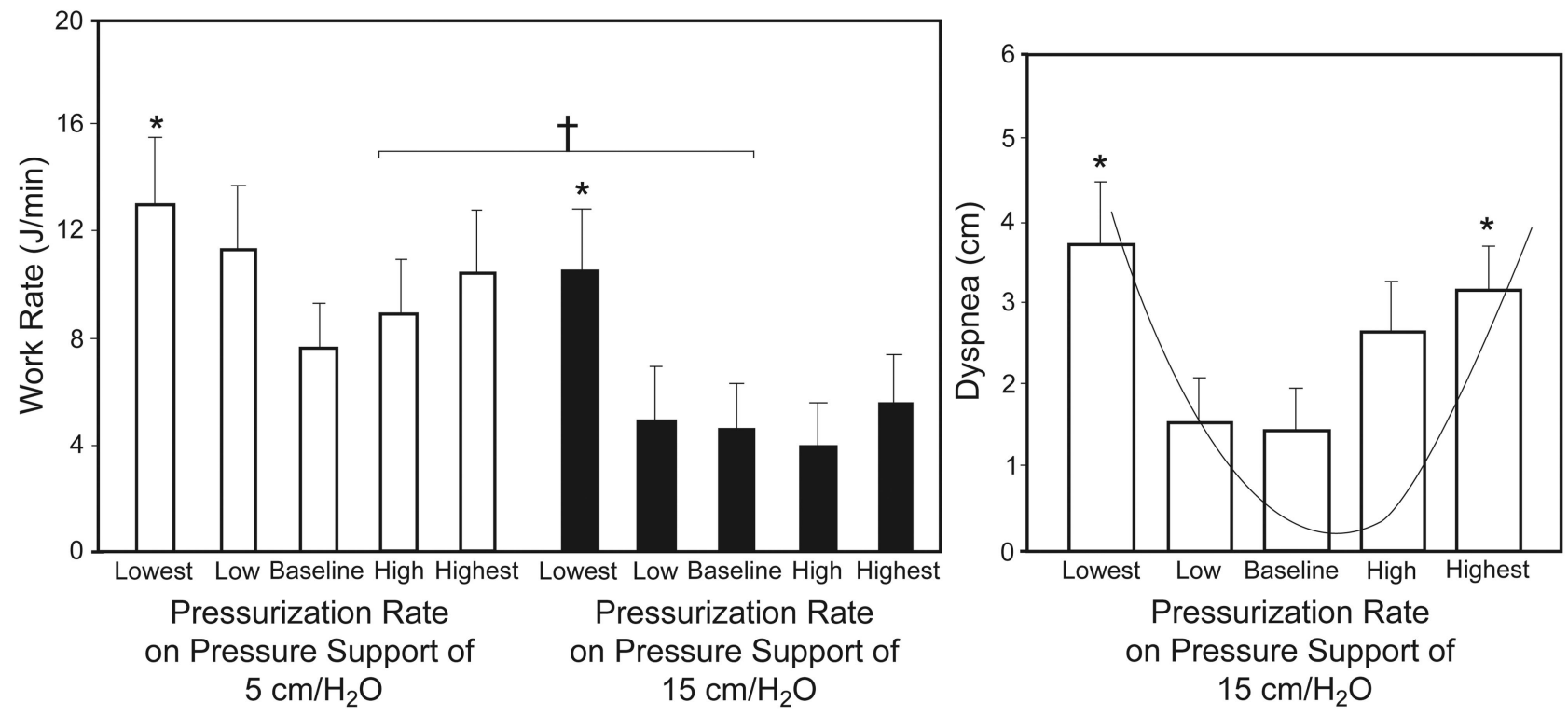

Fig. 4. Effects of pressurization rate on inspiratory muscle work, expressed as work rate, and sensation of dyspnea, or breathing discomfort, in patients with acute lung injury. Left panel shows work rate with pressure support of $5 \mathrm{~cm} \mathrm{H}_{2} \mathrm{O}$ and $15 \mathrm{~cm} \mathrm{H}_{2} \mathrm{O}$ at different pressurization rates of lowest, low, baseline, high, and highest settings with a Bear 1000 ventilator (Allied Healthcare, Riverside, California). The pressurization rate corresponded to an arbitrary scale of -9 (lowest) to +9 (highest), with 0 as the default baseline value. Low and high pressurization rates were set midway between 0 and -9 or +9 , respectively. Right panel demonstrates the perception of dyspnea according to the Borg perceived dyspnea scale at the different pressurization rates, with $0 \mathrm{~cm}$ as no dyspnea and $10 \mathrm{~cm}$ as extremely severe dyspnea. Peak flow rates corresponding to lowest, low, baseline, high, and highest pressurization rates were $0.48,0.67,0.86,0.97$, and $1.12 \mathrm{~L} / \mathrm{s}$, respectively. The sensation of dyspnea follows a U-shape pattern. Bars are mean \pm standard error, $n=10 .{ }^{*} P<.05$ for lowest pressurization rate compared with other pressurization rates for work rate (left panel); compared with low and baseline pressurization rate for sensation of dyspnea (right panel). $† P<.05$ for pressure support of $5 \mathrm{~cm} \mathrm{H}_{2} \mathrm{O}$ compared with pressure support of $15 \mathrm{~cm} \mathrm{H}_{2} \mathrm{O}$ for work rate at all pressurization rates. (From data in Reference 13.)

underlying lung disease or expiratory time constant. In patients with acute lung injury, in whom the expiratory time constant is short, when both pressurization rates and cyclingoff thresholds were varied, for a given pressurization rate, cycling off the ventilator at the lowest or highest percentage of peak flow rate had no effect on work rate (Joules/min, Fig. 5A). ${ }^{15}$ Pressurization rate was the only determinant of work rate. Unloading of inspiratory muscle work was achieved with a high pressurization rate, irrespective of the PS level (see Fig. 5A). Conversely, in patients with COPD, in whom the expiratory time constant is prolonged, the cycling-off threshold has a significant impact on work rate. ${ }^{16}$ When 5 and $15 \mathrm{~cm} \mathrm{H}_{2} \mathrm{O}$ PSV were applied, with and without PEEP, with the cycling-off threshold set at $5 \%$ or $40 \%$ of the peak flow rate, work rate was significantly reduced at a high cycling-off threshold (see Fig. 5B). The high cycling-off threshold results in early breath-termination, compared with that of the low cycling-off threshold, which results in decreased mechanical $\mathrm{T}_{\mathrm{I}}$ and tidal volume $\left(\mathrm{V}_{\mathrm{T}}\right)$, and, consequently, decreased intrinsic PEEP (PEEPi) and triggering time delay. ${ }^{16}$ At a PS of $15 \mathrm{~cm} \mathrm{H}_{2} \mathrm{O}$, varying the cycling-off threshold did not have any impact on work rate. A high PS level unloads inspiratory muscle work significantly, such that the high cycling-off threshold has no further impact on work (see Fig. 5B).

\section{Ventilator Factors as Determinants of Patient-Ventilator Interaction}

Figure 6 shows a simplified concept of patient-ventilator interaction during patient-triggered ventilation. Patient factors consist of patient neural intensity per breath and frequency, whereas ventilator factors consist of the ventilator driving pressure and frequency. ${ }^{17}$ Both neural and ventilator frequencies comprise inspiratory timing (neural $T_{I}$ and mechanical $\mathrm{T}_{\mathrm{I}}$ ) and expiratory timing (neural $\mathrm{T}_{\mathrm{E}}$ and mechanical $\mathrm{T}_{\mathrm{E}}$ ) components. Patient neural intensity per breath is translated into pressure generated by the respiratory muscles $\left(\mathrm{P}_{\text {mus }}\right)$. The ventilator provides the driving pressure $\left(\mathrm{P}_{\mathrm{aw}}\right)$ to deliver gas flow. Both $\mathrm{P}_{\mathrm{mus}}$ and $\mathrm{P}_{\mathrm{aw}}$ make up the pressure applied to overcome the elastance and resistance of the respiratory system, including PEEPi (see Fig. 6). When ventilator-driving pressure is inadequate, flow delivery cannot meet patient flow demand, and flow asynchrony ensues.

In patient-ventilator interaction, feedback mechanisms may have little influence on the patient's neural (respiratory) controller. For instance, during patient-triggered volume-cycled ventilation (ie, volume-controlled continuous mandatory ventilation) if one doubles the ventilator $\mathrm{V}_{\mathrm{T}}$ and increases inspiratory flow rate to maintain mechanical $\mathrm{T}_{\mathrm{I}}$ constant, respiratory frequency decreases little, approximately 

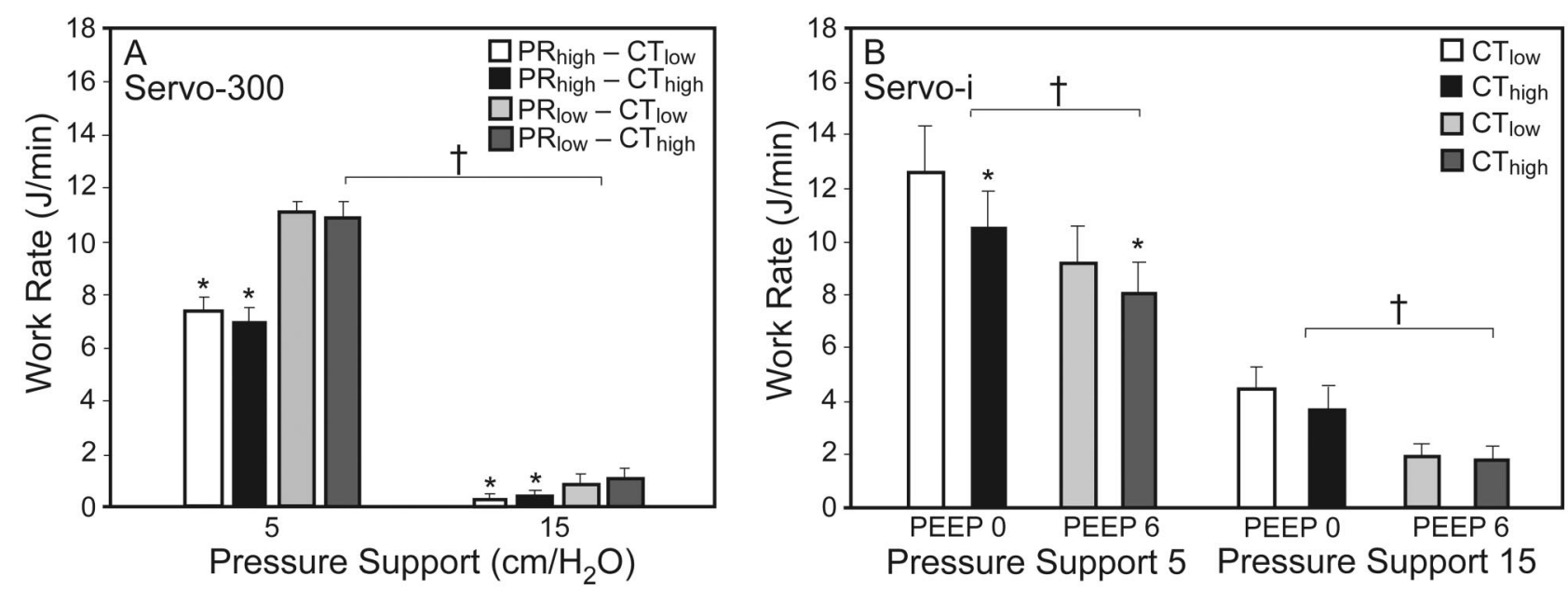

Fig. 5. Work rate as a function of pressurization rate and cycling-off threshold, during pressure-support ventilation of (A) patients with acute lung injury (ALI), and (B) patients with COPD. In the patients with ALI, a Servo-300 (Siemens Elema, Solna, Sweden) was employed, and inspiratory muscle work rate was determined primarily by pressurization rate and pressure-support level. In the patients with COPD, a Servo-I (Maquet, Solna, Sweden) was employed, and inspiratory muscle work rate was determined by the cycling-off threshold and the levels of pressure support and applied positive end-expiratory airway pressure (PEEP). Bars are mean \pm SE. ALI $n=10$. COPD $n=13 .{ }^{*} P<.05$ for pressurization rate high (PRhigh) versus low (PRlow), and cycling-off threshold high (CThigh) versus low (CTlow). $† P<.05$ for pressure support of $5 \mathrm{~cm} \mathrm{H}_{2} \mathrm{O}$ compared with pressure support of $15 \mathrm{~cm} \mathrm{H}_{2} \mathrm{O}$, and for PEEP $0 \mathrm{~cm} \mathrm{H} \mathrm{H}_{2} \mathrm{O}$ versus $6 \mathrm{~cm} \mathrm{H}_{2} \mathrm{O}$. (Adapted from References 15 and 16 .)

$12 \%{ }^{18,19}$ Similarly, in a study with proportional assist ventilation (PAV) in which $\mathrm{V}_{\mathrm{T}}$ increased in response to $\mathrm{CO}_{2}$ challenge, $\mathrm{P}_{\text {mus }}$ decreased only slightly $(14 \%){ }^{20}$ These observations demonstrate that neuromechanical inhibition, via increasing $\mathrm{V}_{\mathrm{T}}$ on respiratory rate and $\mathrm{P}_{\text {mus }}$, is weak. As $\mathrm{V}_{\mathrm{T}}$ increases, the small decrease in respiratory frequency results in shortened $\mathrm{T}_{\mathrm{E}}$, dynamic hyperinflation, a delay in ventilator triggering, and ultimately, ineffective triggering or wasted inspiratory effort, a form of timing or phase asynchrony.

Timing asynchrony occurs when the patient's and ventilator's timing components are mismatched. Timing asynchrony may exist in the form of:

- Ineffective triggering or wasted effort, which can occur during either inhalation or exhalation

- Auto-triggering, which happens when a ventilator breath occurs without patient effort, and is associated with low respiratory drive, prolonged exhalation time in the absence of PEEPi, cardiogenic oscillation, hiccup, low triggering threshold, water in the circuit, or circuit leak

- Double-triggering, which happens when 2 consecutive patient-triggered breath cycles occur with an interval of less than one-half of the mean $T_{I}$, and is associated with short mechanical $T_{I}$ relative to patient neural $T_{I}$

- Short cycling, which occurs when the ventilator breath cycle ceases abruptly, and is associated with high respiratory drive

- Prolonged cycling, which occurs when the ventilator breath cycle is longer than the patient $T_{I}$ (mechanical $T_{I}$ $>$ neural $\mathrm{T}_{\mathrm{I}}$ )
The most common form of timing or phase asynchrony is ineffective triggering or wasted effort $(\mathrm{s})^{5}$; henceforth, the terms ineffective triggering and ineffective or wasted effort(s), will be used interchangeably. Contributing ventilator factors that are responsible for ineffective triggering can be analyzed within the triggering and post-triggering phases.

\section{Triggering Phase}

Trigger Threshold. In the triggering phase, ineffective triggering is associated with an insensitively set trigger threshold and with the ventilator triggering method. An insensitively set trigger threshold induces wasted effort, which can be aggravated by respiratory muscle weakness, blunted respiratory drive, ${ }^{12}$ or conditions that suppress respiratory drive (eg, metabolic or respiratory alkalemia, heavy sedation), or dynamic hyperinflation. ${ }^{21}$

Triggering Methods. Currently, patient-triggered ventilation can occur by 4 methods: pressure triggering, flow triggering, volume triggering, or shape-signal triggering. Replacing pressure triggering with flow triggering does not decrease wasted effort. ${ }^{22}$ Recently, Prinianakis and co-workers ${ }^{3}$ showed that shape-signal triggering results in less wasted effort than flow triggering does. However, because the shape-signal method has highly sensitive triggering, auto-triggering occurs more frequently than with flow triggering. Shape-signal triggering is available on the Vision ventilator (Philips Respironics, Andover, Massachusetts), ${ }^{3}$ which combines the volume-signal and shapesignal methods, whichever occurs first. Shape-signal trig- 


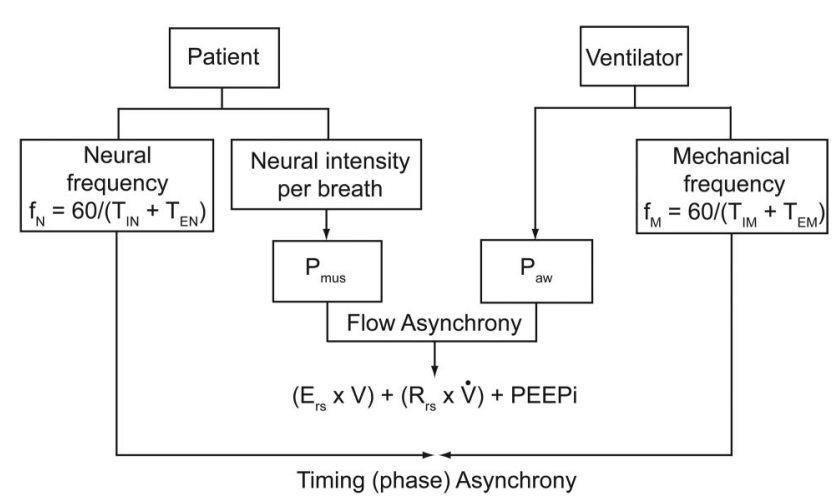

Fig. 6. Determinants of patient-ventilator interaction. The patient's neural intensity per breath is translated into pressure generated by the respiratory muscles $\left(P_{\text {mus }}\right)$. Both the ventilator's driving airway pressure $\left(P_{\text {aw }}\right)$ and $P_{\text {mus }}$ are the pressure applied to overcome respiratory system elastance $\left(E_{R S}\right)$, resistance $\left(R_{R S}\right)$, and intrinsic PEEP (PEEPi). Inadequate $P_{\text {aw }}$ results in unmet patient flow demand, causing flow asynchrony. The patient's neural breathing frequency $\left(f_{N}\right)$ consists of inspiratory $\left(T_{I N}\right)$ and expiratory $\left(T_{E N}\right)$ neural timing. Likewise, the mechanical frequency $\left(\mathrm{f}_{\mathrm{M}}\right)$ consists of mechanical inspiratory $\left(T_{I M}\right)$ or expiratory $\left(T_{E M}\right)$ timing. Mismatching between the timing components results in timing or phase asynchrony. (Adapted from Reference 17.)

gering is activated when the ventilator generates a new shape-signal flow (that is, by offsetting the signal from the actual flow by $0.25 \mathrm{~L} / \mathrm{s}$ and delaying it for $300 \mathrm{~ms}$ ), then crosses the sudden decrease in actual expiratory flow as the patient generates an inspiratory effort (Fig. 7). Likewise, the shape-signal flow can be used to cycle off inspiration. If the shape-signal does not cross the patient's actual expiratory flow-for instance, due to a delay in patient effort—volumetriggering is activated once $6 \mathrm{~mL}$ of volume is accumulated above the baseline flow. ${ }^{3}$ The role of volume-triggering in decreasing wasted effort, in comparison with that of pressure or flow triggering, has not been evaluated.

\section{Post-Triggering Phase}

In the post-triggering phase, ventilator factors contributing to wasted effort include variables that influence the matching of mechanical $T_{I}$ and neural $T_{I}$. These include the level of ventilatory assistance, the cycling-off variable in PSV, the inspiratory flow rate, and to a certain extent the applied PEEP.

Level of Ventilatory Assistance. Leung et al ${ }^{12}$ demonstrated that with PSV the number of wasted efforts increases in proportion to the level of ventilatory assistance. Analysis of the $\mathrm{V}_{\mathrm{T}}$ revealed a higher $\mathrm{V}_{\mathrm{T}}$ in the breaths prior to the wasted efforts than in those of the triggered breaths. Furthermore, the breaths prior to the wasted efforts had an abbreviated mechanical $\mathrm{T}_{\mathrm{E}}$ and higher PEEPi than those of the triggered breaths. In chronically ventilator-dependent patients, decreasing the pressure-support
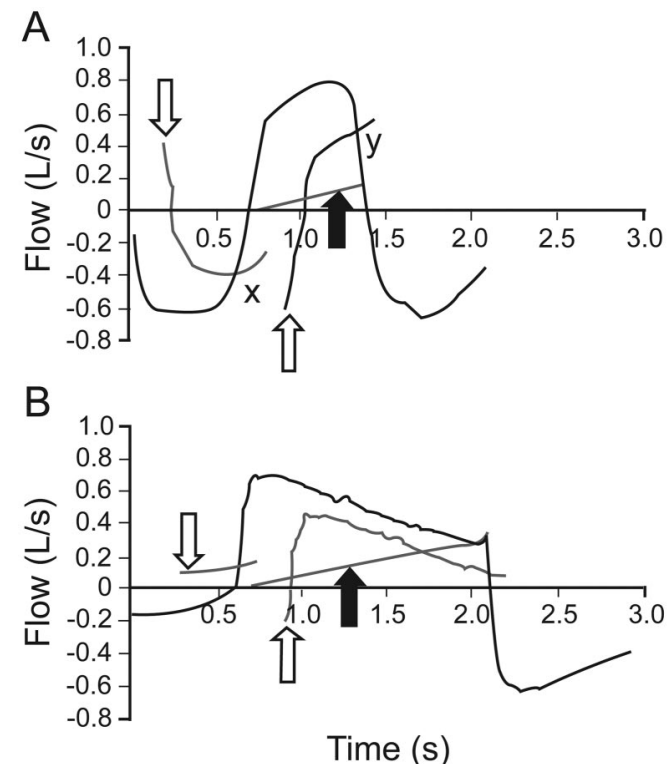

Fig. 7. Shape-signal method of triggering combines shape signal (A) and volume $(B)$ methods of triggering. $A$ : Shape-signal method of triggering (Vision, Philips Respironics, Andover, Massachusetts). The ventilator generates a new shape-signal flow (by offsetting the signal from the actual flow by $0.25 \mathrm{~L} / \mathrm{s}$ and delaying it for $300 \mathrm{~ms}$, thin gray line), and when the shape-signal (first downward open arrow) and actual flow (thick black line) cross at point $X$ (that is, prior to onset of inhalation), the ventilator is triggered for gas delivery. Similarly, inspiration is cycled-off for exhalation when the shape-signal flow (second open upward arrow) crosses the actual flow at point Y. Closed arrows: electronic signal, rising in proportion to actual inspiratory flow in each breath, is activated when the shape-signal method does not occur. B: Volume method of triggering. The volume method of triggering is activated when the actual flow does not cross the generated shape-signal flow until after the onset of inhalation; thus, the shapesignal flow method is delayed. During exhalation, the preset cycle-off threshold (electronic signal) is also activated to cycle off inspiration when the generation of the shape-signal flow for termination of inspiration is delayed. (Courtesy of Philips Healthcare.)

level to an average of $11 \mathrm{~cm} \mathrm{H}_{2} \mathrm{O}$ uniformly eliminated wasted efforts. ${ }^{22}$ The reduced PS level was associated with reduced $\mathrm{V}_{\mathrm{T}}$ and increased $\mathrm{P}_{\mathrm{mus}}$, but at the expense of the development of a rapid shallow breathing pattern and respiratory distress. ${ }^{22}$ Recently, Thille et $\mathrm{al}^{6}$ demonstrated that in patients with weaning difficulty, while maintaining the applied PEEP constant, decreasing the PS from baseline (average of $20 \mathrm{~cm} \mathrm{H}_{2} \mathrm{O}$ ) to optimum (defined as the level of PS that eliminates wasted efforts but does not induce respiratory intolerance) improved the asynchrony index from a median of $45 \%$ to $0 \%$ (Fig. 8A). The asynchrony index is the ratio of wasted efforts to the total number of wasted efforts plus the triggered mechanical breaths collected for $2 \mathrm{~min},{ }^{22}$ and expressed as a percentage. ${ }^{4}$ Wasted efforts were completely eliminated in two thirds of the patients. The optimum PS level (average of $13 \mathrm{~cm} \mathrm{H}_{2} \mathrm{O}$ ) is associated with a mean $\mathrm{V}_{\mathrm{T}}$ of $6.0 \mathrm{~mL} / \mathrm{kg}$, versus $10.2 \mathrm{~mL} / \mathrm{kg}$ at baseline PS, a mechanical $\mathrm{T}_{\mathrm{I}}$ of $0.8 \mathrm{~s}$ 
A

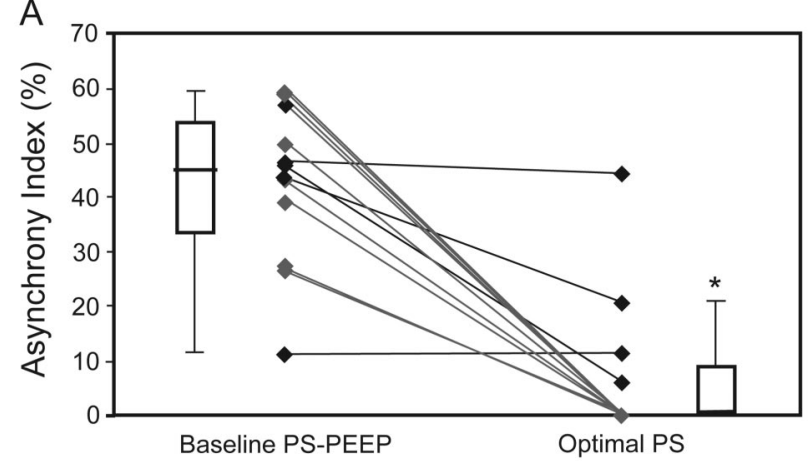

B

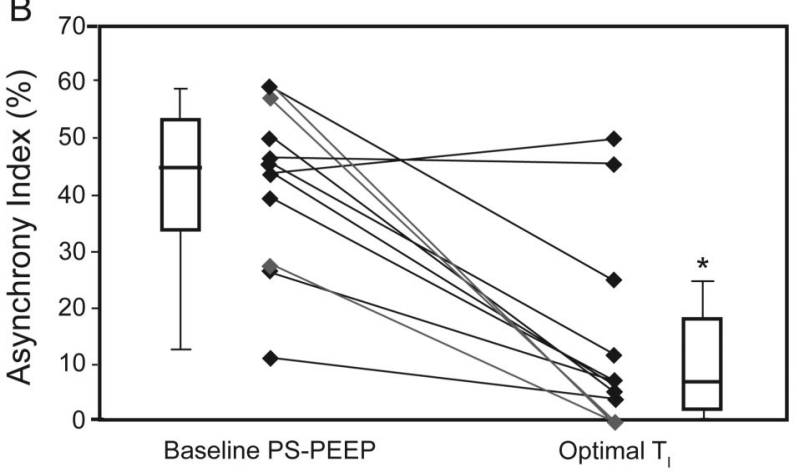

Fig. 8. Asynchrony index at baseline and following optimization of pressure support (PS) level (A), and following optimization of mechanical inspiratory time (mechanical $\left.\mathrm{T}_{1}\right)(\mathrm{B})$. The asynchrony index is the ratio of wasted efforts to the total of wasted efforts plus triggered mechanical breaths collected for 2 minutes, expressed as a percentage. Optimizing the PS (Avea, Viasys Healthcare, Conshohocken, Pennsylvania) level (panel A) or mechanical $T_{1}$ (panel B) improves the asynchrony index. The optimal PS level is defined as the PS at which wasted efforts are eliminated when the PS is reduced by increments of $2 \mathrm{~cm} \mathrm{H}_{2} \mathrm{O}$, or when the patient shows poor tolerance, whichever occurs first. A positive end-expiratory airway pressure of $5 \mathrm{~cm} \mathrm{H}_{2} \mathrm{O}$ is maintained at baseline and optimal PS. In 8 of 12 patients, optimizing the $\mathrm{PS}$ reduced the asynchrony index to $0 \%(\mathrm{~A})$. In panel $\mathrm{B}$, mechanical $T_{1}$ is adjusted until optimal mechanical $T_{1}$ is achieved. Optimal mechanical $T_{1}$ is obtained by increasing the cycling-off threshold by increments of $10 \%$ of peak flow rate. If the maximum cycling-off threshold is reached ( $45 \%$ of peak flow) and wasted efforts persist, the insufflation time is reduced by steps of $0.2 \mathrm{~s}$ from the mean insufflation time (by increasing the pressurization rate) until wasted efforts are eliminated or the patient develops respiratory intolerance, as defined above. Values are median and interquartile range. ${ }^{*} P<.01$ compared to baseline PS and PEEP. (From data in Reference 6.)

versus $1.3 \mathrm{~s}$, and a dynamic PEEPi of $1.1 \mathrm{~cm} \mathrm{H}_{2} \mathrm{O}$ versus $1.8 \mathrm{~cm} \mathrm{H}_{2} \mathrm{O}$, respectively.

Cycling-Off Threshold. To decrease wasted efforts, Thille et $\mathrm{al}^{6}$ also employed a different approach: by adjusting the cycling-off variable from a baseline of $25 \%$ of peak flow to a maximum value of $45 \%$, mechanical $\mathrm{T}_{\mathrm{I}}$ was reduced until an optimal mechanical $T_{I}$ was achieved. If wasted efforts persisted, the insufflation time was further decreased by steps of $0.2 \mathrm{~s}$ until wasted efforts were eliminated or respiratory intolerance ensued. At optimal mechanical $\mathrm{T}_{\mathrm{I}}$, the asynchrony index decreased by $38 \%$ (see Fig. $8 \mathrm{~B}$ ). $\mathrm{V}_{\mathrm{T}}$ decreased to an average of $7 \mathrm{~mL} / \mathrm{kg}$, mechanical $\mathrm{T}_{\mathrm{I}}$ decreased to $0.8 \mathrm{~s}$, and dynamic PEEPi decreased to $1.5 \mathrm{~cm} \mathrm{H}_{2} \mathrm{O}$. Thus, decreasing the PS level or reducing mechanical $\mathrm{T}_{\mathrm{I}}$ by adjusting the cycling-off threshold is an effective method for reducing wasted efforts, and is associated with reduced $\mathrm{V}_{\mathrm{T}}$, mechanical $\mathrm{T}_{\mathrm{I}}$, and PEEPi, and therefore with a better match between patient and ventilator $\mathrm{T}_{\mathrm{I}}$.

In selecting the cycling-off threshold it is important to take into account the respiratory system's time constantthat is, the time required to empty approximately two thirds of the expired volume - the product of resistance and compliance. In patients with COPD, the time constant is prolonged, and setting the cycling-off threshold high (as a percentage of the peak flow rate), improves matching of mechanical $T_{I}$ and neural $T_{I}$, and reduces wasted efforts (Fig. 9A). ${ }^{23,24} \mathrm{~V}_{\mathrm{T}}$, neural $\mathrm{T}_{\mathrm{I}}$, triggering time delay, and PEEPi decrease significantly with the cycling-off threshold set high, as compared with low. ${ }^{23}$ Conversely, in patients with acute lung injury, the time constant is short; a high cycling-off threshold results in premature breath-termination and causes re-triggering (double-triggering) or premature opening of the exhalation valve (see Fig. 9B). ${ }^{24}$

Inspiratory Flow Rate. With patient-triggered volumecontrol ventilation, a low set inspiratory flow rate that is less than patient ventilatory demand induces not only flow asynchrony (see Fig. 6) but also mismatching between mechanical $T_{I}$ and neural $T_{I}$. Mechanical $T_{I}$ is prolonged relative to neural $T_{I}$, encroaching into patient $T_{E}$ such that the next breath occurs at a high lung volume, above its resting endexpiratory volume and resulting in ineffective triggered breaths. This type of wasted effort can be corrected by increasing the inspiratory flow rate, or, when pressure-control time-cycled ventilation is employed, by shortening the $\mathrm{T}_{\mathrm{I}}{ }^{25}$

Applied PEEP. Thille et $\mathrm{al}^{6}$ did not find PEEP application useful in reducing wasted efforts, because PEEPi was less than the applied PEEP. Their findings ${ }^{6}$ contrasted with those of Nava et al, ${ }^{21}$ in which wasted efforts decreased significantly, from a mean \pm standard error of $19 \pm 5.7 \%$ without PEEP to $4 \pm 2.5 \%$ when a PEEP equivalent to $75 \%$ of the measured static PEEPi was applied. PEEPi ranged from 3 to $20 \mathrm{~cm} \mathrm{H}_{2} \mathrm{O}$. Applying PEEP to improve wasted efforts will have to be customized to the degree of static PEEPi. However, measurement of PEEPi is frequently not feasible without the administration of heavy sedation or paralytics.

\section{Ventilator Modes for Improving Patient-Ventilator Interaction}

Currently, only 2 ventilator modes-PAV ${ }^{26}$ and neurally adjusted ventilatory assist (NAVA) ${ }^{27}$-are capable of 

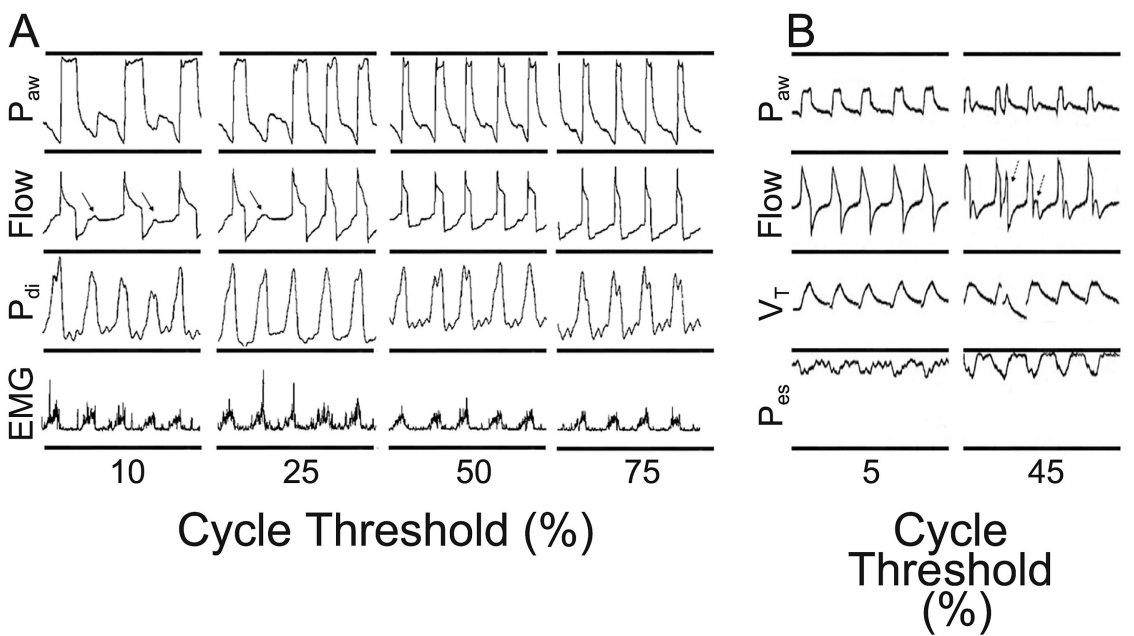

Fig. 9. Effects of increasing the cycling-off threshold according to prolonged (A) or short (B) time constant of the respiratory system. Increasing the cycling-off threshold (CT) (Galileo Gold, Hamilton Medical, Rhäzuns, Switzerland) from 10\% to $50-75 \%$ in patients with a prolonged time constant (COPD) eliminates wasted efforts. In contrast, panel B shows that increasing the cycling-off threshold (PuritanBennett 840 , Mallinckrodt, Pleasanton, California) from $5 \%$ to $45 \%$ in patients with a short time constant (acute lung injury or acute respiratory distress syndrome) induces double-triggering or premature opening of the exhalation valve. The arrows (A) point to wasted efforts. The first arrow (B) points to double-triggering. The second arrow (B) points to premature opening of the exhalation valve. $P_{\text {aw }}=$ airway pressure. $\mathrm{P}_{\mathrm{TD}}=$ transdiaphragmatic pressure. $\mathrm{EMG}=$ electromyogram signal of diaphragmatic electrical activity. $\mathrm{V}_{\mathrm{T}}=$ tidal volume. $\mathrm{P}_{\mathrm{es}}=$ esophageal pressure. (Adapted from References 23 and 24, with permission.)

decreasing patient-ventilator asynchrony, and will be mentioned only briefly in this review. The trigger variable differs between these 2 modes. PAV employs pneumatic triggering, with either pressure or flow to initiate the breath. In contrast, triggering with NAVA employs diaphragmatic electrical activity, a signal near proximal to the respiratory controller, and, therefore, avoids triggering delay, as occurs with dynamic hyperinflation or circuit leaks. ${ }^{28}$ Diaphragmatic electrical activity signal is used not only to initiate but also to assist and cycle off inspiration. Triggering of the ventilator occurs when the diaphragmatic electrical signal, above a manually set trigger threshold, is detected. Setting the trigger threshold above the baseline diaphragmatic electrical activity noise level avoids autotriggering. 27,29

The efficacy of both PAV and NAVA in improving patient-ventilator synchrony was compared with PSV. ${ }^{26,27}$ In patients receiving PAV or PSV for $48 \mathrm{~h}$, wasted efforts with an asynchrony index of greater than $10 \%$, were observed in $1.3 \%$ (10/744 measurements) of patients receiving PAV, compared with $9.6 \%$ (67/696 measurements) of patients receiving PSV. In a short-term trial with 14 patients with 2 levels of NAVA and PSV, in which airway pressure with NAVA was matched to that with PSV (an average of $10.6 \mathrm{~cm} \mathrm{H}_{2} \mathrm{O}$ and $17.4 \mathrm{~cm} \mathrm{H}_{2} \mathrm{O}$ for low and high support levels, respectively), wasted efforts were observed in 6 of 14 patients. In the patients with wasted efforts, the mean \pm SD wasted efforts with low and high PSV were $5 \pm 4 \%$ and $31 \pm 26 \%$, respectively, while complete patient-ventilator synchrony was achieved with NAVA.

\section{Proposed Algorithm to Improve Patient-Ventilator Synchrony}

Figure 10 shows a proposed algorithm that can be applied at the bedside to decrease or eliminate wasted efforts, based on the studies discussed above. Commonly, a low level of PEEP $\left(5 \mathrm{~cm} \mathrm{H}_{2} \mathrm{O}\right)$ is applied at the onset of mechanical ventilation. In this case, PEEP can be maintained while taking the steps shown in the algorithm. When one can measure static PEEPi-recognizing that in patienttriggered breaths this may not be feasible-for a PEEPi greater than $5 \mathrm{~cm} \mathrm{H}_{2} \mathrm{O}$, apply PEEP of $75-80 \%$ of static PEEPi. ${ }^{21}$ For a PEEPi of less than $5 \mathrm{~cm} \mathrm{H}_{2} \mathrm{O}$, or immeasurable, maintain $5 \mathrm{~cm} \mathrm{H}_{2} \mathrm{O}$ PEEP. If wasted efforts with asynchrony index of greater than $10 \%$ persist, one can increase applied PEEP by $1 \mathrm{~cm} \mathrm{H}_{2} \mathrm{O}$ increments to a maximum of $8 \mathrm{~cm} \mathrm{H}_{2} \mathrm{O}$. Following this maneuver, if wasted efforts persist, the assist level, whether in the form of pressure or volume assist, is adjusted to achieve a $\mathrm{V}_{\mathrm{T}}$ of 6-8 mL/kg. ${ }^{6}$ Afterwards, one can increase the set inspiratory flow rate with volume-controlled continuous mandatory ventilation ${ }^{25}$ or increase the pressurization rate with pressure-control ventilation. ${ }^{15}$ In addition, with time-cycled pressure-control ventilation, $\mathrm{T}_{\mathrm{I}}$ can be decreased while maintaining patient comfort. With PSV, one can adjust the cycling-off threshold, taking into account the respiratory system's time constant. ${ }^{23,24}$ In patients with a prolonged time constant (ie, COPD), the flow cycling-off threshold is adjusted upward as a percentage of peak flow rate, ${ }^{23}$ while in patients with a short time constant (ie, acute lung injury 


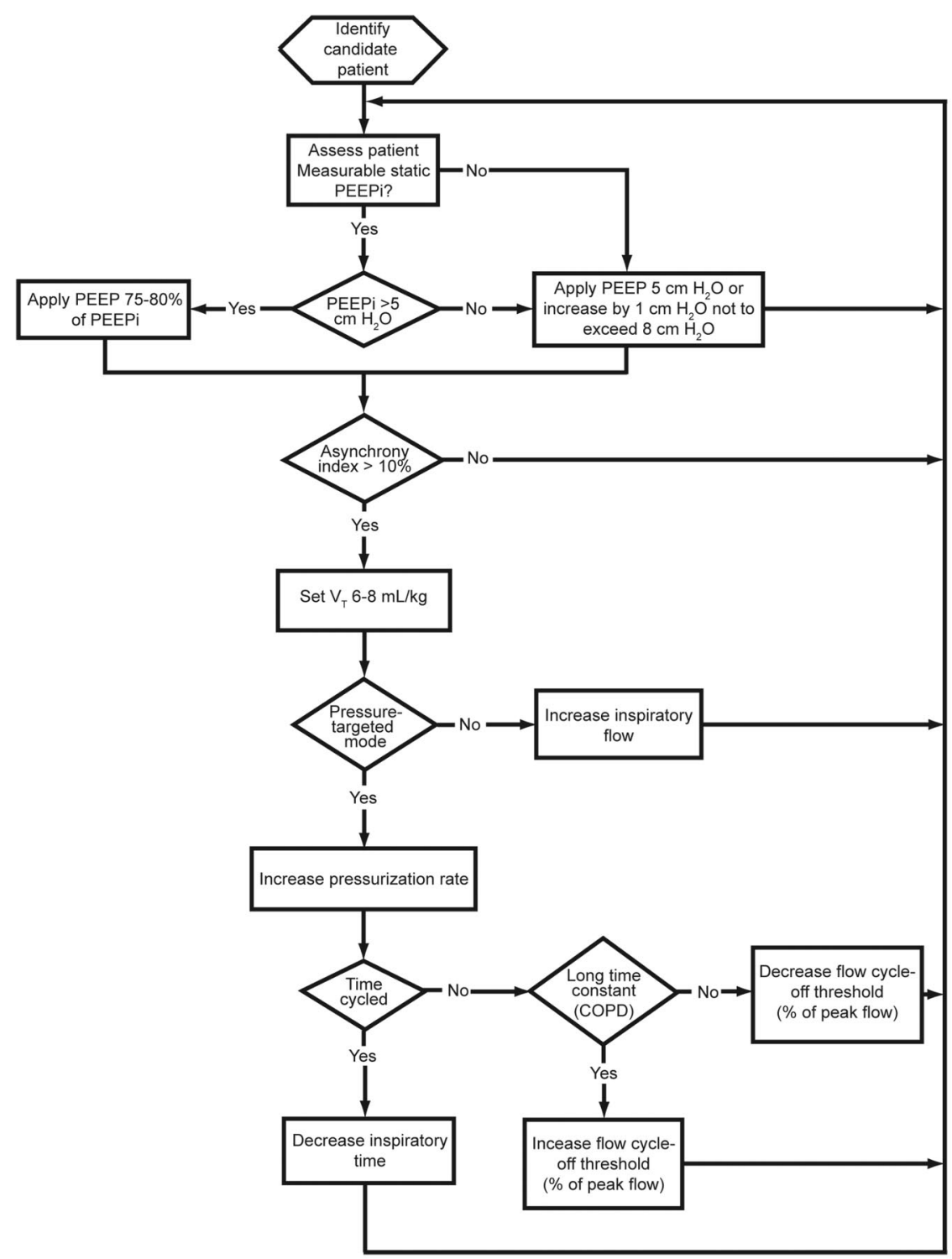

Fig. 10. An algorithm showing the steps to take at the bedside in order to eliminate or improve wasted efforts. Patients with wasted efforts will be identified and assessed. If static intrinsic PEEP (PEEPi) is measurable-recognizing that in patient-triggered breaths this may not be feasible - and greater than $5 \mathrm{~cm} \mathrm{H}_{2} \mathrm{O}$, apply PEEP of $75-80 \%$ of static PEEPi. If PEEPi is immeasurable or $\leq 5 \mathrm{~cm} \mathrm{H}_{2} \mathrm{O}$, apply PEEP of $5 \mathrm{~cm} \mathrm{H}_{2} \mathrm{O}$. If wasted efforts persist, increase the applied PEEP by $1 \mathrm{~cm} \mathrm{H}_{2} \mathrm{O}$ increments to a maximum of $8 \mathrm{~cm} \mathrm{H}_{2} \mathrm{O}$. When wasted efforts persist and the asynchrony index is $\geq 10 \%$, adjust the assist level to achieve a $V_{\mathrm{T}}$ of $6-8 \mathrm{~mL} / \mathrm{kg}$. Next, is the patient on a pressure-targeted mode? If not (on volume-control continuous mandatory ventilation, increase set inspiratory flow rate). If patient is on pressure-targeted ventilation, increase pressurization rate. If pressure-targeted is time-cycled, reduce set inspiratory time. If the pressure-targeted ventilation is flow-cycled (pressure-support ventilation) and wasted efforts persist, adjust the flow-cycling-off threshold (percent of peak flow), taking into account the respiratory system's time constant. In patients with a prolonged time constant (eg, COPD), increase the flow-cycling-off threshold; and in patients with a short time constant (eg, acute lung injury or acute respiratory distress syndrome), decrease the flowcycling-off threshold. It may be necessary to fine-tune the cycling-off threshold, mechanical inspiratory time $\left(T_{1}\right)$ and tidal volume $\left(V_{T}\right)$, as adjusting the cycling-off threshold may result in a concomitant decrease in $\mathrm{V}_{\mathrm{T}}$ and/or mechanical $\mathrm{T}_{1}$. The patient needs to be reassessed and the steps may be halted at any level when the asynchrony index has successfully been reduced to less than $10 \%$.

or acute respiratory distress syndrome) the cycling-off threshold is adjusted downward. ${ }^{24}$ With a high-set cyclingoff threshold, mechanical $\mathrm{T}_{\mathrm{I}}$ and $\mathrm{V}_{\mathrm{T}}$ may decrease. It may be necessary to fine-tune the cycling-off threshold or adjust mechanical $T_{I}$ and $V_{T}$ to avoid respiratory distress.
The patient needs to be reassessed and the step may be halted at any level in the proposed algorithm when the asynchrony index has successfully been reduced to less than $10 \%$. However, this algorithm remains to be prospectively tested for its efficacy. 


\section{REFERENCES}

1. Sassoon CS. Mechanical ventilator design and function: the trigger variable. Respir Care 1992;37(9):1056-1069.

2. Sassoon CS, Giron AE, Ely EA, Light RW. Inspiratory work of breathing on flow-by and demand-flow continuous positive airway pressure. Crit Care Med 1989;17(11):1108-1114.

3. Prinianakis G, Kondili E, Georgopoulos D. Effects of the flow waveform method of triggering and cycling on patient-ventilator interaction during pressure support. Intensive Care Med 2003;29(11):1950-1959.

4. Thille AW, Rodriguez P, Cabello B, Lellouche F, Brochard L. Patient-ventilator asynchrony during assisted mechanical ventilation. Intensive Care Med 2006;32(10):1515-1522.

5. de Wit M, Miller KB, Green DA, Ostman HE, Gennings C, Epstein SK. Ineffective triggering predicts increased duration of mechanical ventilation. Crit Care Med 2009;37(10):2740-2745

6. Thille AW, Cabello B, Galia F, Lyazidi A, Brochard L. Reduction of patient-ventilator asynchrony by reducing tidal volume during pressure-support ventilation. Intensive Care Med 2008;34(8):1477-1486.

7. de Wit M, Pedram S, Best AM, Epstein SK. Observational study of patient-ventilator asynchrony and relationship to sedation level. J Crit Care 2009;24(1):74-80.

8. Lellouche F, Mancebo J, Jolliet P, Roeseler J, Schortgen F, Dojat M, et al. A multicenter randomized trial of computer-driven protocolized weaning from mechanical ventilation. Am J Respir Crit Care Med 2006;174(8):894-900.

9. Burns KE, Lellouche F, Lessard MR. Automating the weaning process with advanced closed-loop systems. Intensive Care Med 2008; 34(10): 1757-1765.

10. Thille AW, Lyazidi A, Richard JC, Galia F, Brochard L. A bench study of intensive-care-unit ventilators: new versus old and turbinebased versus compressed gas-based ventilators. Intensive Care Med 2009;35(8):1368-1376.

11. Richard JC, Carlucci A, Breton L, Langlais N, Jaber S, Maggiore S, et al. Bench testing of pressure support ventilation with three different generations of ventilators. Intensive Care Med 2002;28(8):1049-1057.

12. Leung P, Jubran A, Tobin MJ. Comparison of assisted ventilator modes on triggering, patient effort, and dyspnea. Am J Respir Crit Care Med 1997;155(6):1940-1948.

13. Chiumello D, Pelosi P, Croci M, Bigatello LM, Gattinoni L. The effects of pressurization rate on breathing pattern, work of breathing, gas exchange and patient comfort in pressure support ventilation. Eur Respir J 2001;18(1):107-114.

14. Manning HL, Molinary EJ, Leiter JC. Effect of inspiratory flow rate on respiratory sensation and pattern of breathing. Am J Respir Crit Care Med 1995;151(3 Pt 1):751-757.

15. Chiumello D, Pelosi P, Taccone P, Slutsky A, Gattinoni L. Effect of different inspiratory rise time and cycling off criteria during pressure support ventilation in patients recovering from acute lung injury. Crit Care Med 2003;31(11):2604-2610.
16. Chiumello D, Polli F, Tallarini F, Chierichetti M, Motta G, Azzari S, et al. Effect of different cycling-off criteria and positive end-expiratory pressure during pressure support ventilation in patients with chronic obstructive pulmonary disease. Crit Care Med 2007;35(11):2547-2552.

17. Tom LR, Sassoon CSH. Patient-ventilator interactions. In: MacIntyre NR, Branson RD editors. Mechanical ventilation, 2nd edition. Philadelphia: Elsevier; 2009:182-197.

18. Puddy A, Patrick W, Webster K, Younes M. Respiratory control during volume-cycled ventilation in normal humans. J Appl Physiol 1996;80(5):1749-1758.

19. Laghi F, Segal J, Choe WK, Tobin MJ. Effect of imposed inflation time on respiratory frequency and hyperinflation in patients with chronic obstructive pulmonary disease. Am J Respir Crit Care Med 2001;163(6):1365-1370.

20. Georgopoulos D, Mitrouska I, Webster K, Bshouty Z, Younes M. Effects of inspiratory muscle unloading on the response of respiratory motor output to $\mathrm{CO}_{2}$. Am J Respir Crit Care Med 1997;155(6):20002009.

21. Nava S, Bruschi C, Rubini F, Palo A, Iotti G, Braschi A. Respiratory response and inspiratory effort during pressure support ventilation in COPD patients. Intensive Care Med 1995;21(11):871-879.

22. Chao DC, Scheinhorn DJ, Stearn-Hassenpflug M. Patient-ventilator trigger asynchrony in prolonged mechanical ventilation. Chest 1997; 112(6): 1592-1599

23. Tassaux D, Gainnier M, Battisti A, Jolliet P. Impact of expiratory trigger setting on delayed cycling and inspiratory muscle workload. Am J Respir Crit Care Med 2005;172(10):1283-1289.

24. Tokioka H, Tanaka T, Ishizu T, Fukushima T, Iwaki T, Nakamura Y, Kosogabe Y. The effect of breath termination criterion on breathing patterns and the work of breathing during pressure support ventilation. Anesth Analg 2001;92(1):161-165.

25. Georgopoulos D, Prinianakis G, Kondili E. Bedside waveforms interpretation as a tool to identify patient-ventilator asynchronies. Intensive Care Med 2006;32(1):34-47.

26. Xirouchaki N, Kondili E, Vaporidi K, Xirouchakis G, Klimathianaki M, Gavriilidis G, et al. Proportional assist ventilation with loadadjustable gain factors in critically ill patients: comparison with pressure support. Intensive Care Med 2008;34(11):2026-2034.

27. Spahija J, de Marchie M, Albert M, Bellemare P, Delisle S, Beck J, et al. Patient-ventilator interaction during pressure support ventilation and neurally adjusted ventilatory assist. Crit Care Med 2010; 38(2):518-526.

28. Sinderby C, Beck J. Proportional assist ventilation and neurally adjusted ventilatory assist-better approaches to patient ventilator synchrony? Clin Chest Med 2008;29(2):329-342.

29. Sinderby C, Beck J, Spahija J, de Marchie M, Lacroix J, Navalesi P, Slutsky AS. Inspiratory muscle unloading by neurally adjusted ventilatory assist during maximal inspiratory efforts in healthy subjects. Chest 2007;131(3):711-717.

\section{Discussion}

Kallet: A lot of the asynchrony I see in ALI [acute lung injury] patients stems from having an inspiratory time that's too short. What I find is that when someone's managed with the ARDS [acute respiratory distress syndrome] Network low-tidal-volume protocol, ${ }^{1}$ clinicians jack up the in- spiratory flow to 60 or $70 \mathrm{~L} / \mathrm{min}$ to make the patient less dyspneic. Sometimes, with low tidal volumes we're cutting the inspiratory time down to 0.5 or 0.6 seconds. It end ups that the patient's neural inspiratory time is longer than the ventilator inspiratory time, and they start double-triggering.

I think some of the asynchrony we see in ALI is inescapable and you need to make a decision that is least harmful. For me, I'd rather keep a high inspiratory flow rate and extend the inspiratory time a bit by creating more of a pause time. Unfortunately, patients often continue to inspire during the pause phase, but it cuts down on their ability to double-trigger breaths and get a big tidal volume. The down side is that work of breathing is worse, and as we've found 
to our dismay, it can exacerbate pulmonary edema. ${ }^{2}$

I think the conundrum we face with asynchrony in ALI patients is that we don't have very good options to choose from: either we heavily sedate them, liberalize their tidal volume, or continue to try to restrain their tidal volume. That means that we try the strategies I just mentioned, or we reduce inspiratory flow rate to try to match their inspiratory time, which also increases work of breathing. ${ }^{3}$

1. The Acute Respiratory Distress Syndrome Network. Ventilation with lower tidal volumes as compared with traditional tidal volumes for acute lung injury and the acute respiratory distress syndrome. $\mathrm{N}$ Engl J Med 2000;342(18):1301-1308.

2. Kallet RH, Alonso JA, Luce JM, Matthay MA Exacerbation of acute pulmonary edema during assisted mechanical ventilation using a low-tidal volume, lung-protective ventilator strategy. Chest 1999;116(6): 1826-1832.

3. Kallet RH, Alonso JA, Diaz M, Campbell AR, Mackersie RC, Katz JA. The effects of tidal volume demand on work of breathing during simulated lung-protective ventilation. Respir Care 2002;47(8):898-909.

Sassoon: I agree that it depends on the patient's expiratory time constant, short or prolonged time constant: the latter in patients with COPD. In patients with short time constant, as in ARDS, to set the inspiratory time too short may not be a good idea.

Branson: It strikes me again how important the patient is. In Scott's [Epstein] talk we were talking about the asynchrony index in COPD versus ARDS after trauma or surgery, and I think the presence of dynamic hyperinflation or auto-PEEP is what's really key to the asynchrony index. What's good in the pressure-support setting for the patient with COPD, in terms of both triggering and cycling, is not good for the patient with ALI. It goes back to the education issue that Bob [Kacmarek] raised: we can't treat everybody the same. People have to understand the un- derlying physiology and set the ventilator appropriately.

Kacmarek: Well, I took it differently: it's the clinician that's important. I really liked your first slide where you added the clinician into the patientventilator diagram. Although the patients all respond differently, it's the clinician's recognition of the differences in those patients that truly makes the difference in how well the patient is managed.

I want to go back to Sai's [Parthasarathy] comments about the need for automated approaches to ventilatory support, particularly in patients breathing spontaneously. We could sit here and design the types of responses that were necessary, and by the time this symposium was done create the appropriate algorithms to manage, for example, pressure support. No offense to our co-workers, but all of us have been in many institutions, and the fact of the matter is that people don't pay attention to these subtleties. The majority of patients are ventilated by a standard approach, and you ask staff to look at a waveform and try to analyze it, staff have no idea of what they're looking at. So I am not sure that we can achieve the needed outcome by education. I believe it will take a better approach to closed-loop control to improve synchrony.

Parthasarathy: It goes back to the education team that Dave [Pierson] was talking about: it's such a vital issue. I have fellows come to me and groan because I ask them what the compliance is today, what's the resistance today? They say, you're the only guy who asks that! And secretly I'm thinking, what the heck are they doing? I really think you have to subscribe to it and do it, or if you don't do it, you should just focus on the VAP [ventilator-associated pneumonia] in that patient, and I've got all these nurses chasing me as to whether I'm washing my hands and all of that.
My question is about double-triggering. There was one patient with ARDS on the ventilator and set to receive low tidal volume at $6 \mathrm{~mL} / \mathrm{kg}$ ideal body weight, but the patient was double-triggering nearly every other breath. Does that really mean that the patient is receiving the low tidal volume set on the machine, when they're double-triggering? If they're set at $400 \mathrm{~mL}$, are they not actually getting much more, such as $800 \mathrm{~mL}$ ?

Sassoon: I think the flow rate setting and the increase in respiratory drive have to be considered as well. In double-triggering, most of the time the neural inspiratory timing is greater than the mechanical inspiratory timing, so you have to adjust.

Parthasarathy: That's the down side. If someone wasn't paying attention to double-triggering, you could actually change your patient outcome considerably.

Sassoon: Yes. I think the most important thing when we return home is to try to establish better education for our RTs [respiratory therapists]. Even at my institution we have a Puritan Bennett 840 with PAV [proportional assist ventilation], and not a single RT knows how to use it, so that's a problem.

Younes:* I'd like to add support to what Bob and Sai are saying. I'm the oldest one here by far, and I spent the first 20 years of my career trying to teach the fellows and RTs and ICU doctors how to think about mechanics and interactions, and after 20 years I gave up and I decided it has to be automated, because it's too complicated and everybody is so busy. You have to spend a couple of years just to figure it out.

\footnotetext{
* Magdy Younes MD FRCP(C) PhD, Deprtment of Medicine, University of Manitoba, Winnipeg, Manitoba, Canada.
} 
Sassoon: The down side of automation is that you still have to have the knowledge on what to do if something goes wrong.

Younes: The problem with automation is how sophisticated it is. You can have all kinds of algorithms.

Pierson: Every time I hear the analogy of the airline checks brought up and directed into our arena it bothers me. Is the critically ill patient or the home-care patient with a sleep disorder just a more complex system that takes us more time to figure out how to fully automate and implement a Toyota system or Boeing checklist, or is there something fundamentally different about the clinical setting that's not going to allow us to do this? Is it just a matter of logistics, or is there something fundamentally different about the system that we have?

Hurford: The thing is that an airplane is defined, and an airplane is standard, and it's always an airplane. It doesn't turn into a satellite, or a helicopter, or a U-boat, whereas a patient may start out with COPD, then get pneumonia, then get bronchospasm: they change. We need algorithms that define diagnosis: not necessarily therapy. We aren't lumping here. We're not talking about an asthmatic versus someone with COPD versus a 500-pound guy who fell down the steps. Those patients are going to have very different patterns on the ventilator. I think it makes it much more difficult than to come up with a remote flight algorithm for a drone.

Branson: I'd take it one step further, having flown a plane myself. If I check the plane and find the radio doesn't work and there's only a quarter tank of gas, I don't fly it. We don't have that luxury with a patient. The patient can't communicate, but we still have to deal with them. If the patient doesn't have enough fluid, from blood loss or whatever, we still have to ventilate them. I think it's disingenuous. I think we can learn from the airline industry as to preventing errors, but I think we have nothing to learn from the airline industry in how we deal with a patient as compared to an airplane.

Catherine, you didn't mention $\mathrm{Du},{ }^{1}$ who came up with an automated system for setting the flow cycle of pressure support. And the Newport ventilators actually do automated rise time and automated flow cycling. Is the issue there that that system hasn't been tested sufficiently, or is the issue that Newport has such a small market that it doesn't care if nobody knows if it works?

\section{Du HL, Amato MB, Yamada Y. Automa- tion of expiratory trigger sensitivity in pres- sure support ventilation. Respir Care Clin} N Am 2001;7(3):503-517.

Sassoon: Probably the Newport has not been sufficiently tested because of its small market. It would be interesting to see how the Newport compares to ventilators with manually adjustable settings.

Branson: So the system essentially uses compliance and resistance to create the expiratory time constant, and changes the cycling percentage based on the expiratory time constant, and also pressure rise at the end of inspiration. Outside of their original paper I don't know if anybody has really looked at it seriously.

Kacmarek: We have a paper that we're about submit in which we looked at default ventilator settings for triggering, rise time, and cycling criteria compared to what we could set optimally to eliminate these issues of asynchrony. Our manual settings were clearly better.

But let me go back to the airplane versus patient. Bill [Hurford] commented about how all patients are different, but all those differences translate to differences in measurable variables. I don't think the etiology of the problem has a big impact; what's important is the impact the problem has on cardiovascular-pulmonary interaction. Those interactions are programmable! It seems to me that if you can fly a plane with algorithms, we should be able to manage synchrony in most patients. If we are willing to put the time and money into developing the correct algorithms, we can better manage synchrony. I don't think it eliminates the need for RTs or physicians at the bedside; I think it intensifies the need. As Catherine indicated, they have to be smarter and better able to look at trends and how the particular algorithm is applied.

The automated pilot on an airplane has never eliminated the need for an actual pilot, and the same is true when we talk about closed-loop control of mechanical ventilation. I think closedloop control is critical, because I, like Magdy, have been trying to teach the same thing over and over for 25 years. How many times have we given presentations about asynchrony-and the slides we're using today aren't that different from the slides we used 25 years ago. We just add more studies that show the same things that we knew 25 years ago about asynchrony. Everything we're talking about here, from trigger asynchrony to auto-PEEP, John Marini and others published back in the 1980s.

Parthasarathy: I want to point out that the 100,000 Lives Saved Campaign from the healthcare system is derived from the airline industry. It was the fact that we found it appalling that we could kill 100,000 patients and that was not on the radar, whereas the airline industry kills a few hundred people and it's all over the news. They were, like, What is wrong with this picture? The airline industry already helped the healthcare industry, with the 100,000 Lives Saved Campaign.

Kallet: To try to answer Dave's [Pierson] question, I think there's the cultural component in all of this. I think there's been a certain amount of arro- 
gance in the medical field, where physicians or RTs are stubborn about how they deliver patient care, regardless of the evidence. I don't think society is going to accept our attitudes much longer. In listening closely to the recent healthcare debate, I was struck by how often major politicians cited the cost-cutting benefits of evidencebased medicine. In the coming years, clinicians are not going to be allowed to just ignore therapies that clearly improve outcomes. Whether some of these issues can be solved by closed-loop control of ventilation, or just some type of financial punishment for not implementing care that's been shown to improve outcomes, change is coming!

Branson: The difference between airline process improvement and making sure the patients gets gastrointestinal prophylaxis, DVT [deep venous thrombosis] prophylaxis, making sure the bed is up-those things are the things that the airlines do right. But comparing the patient/ventilator to a plane/pilot is where I think the whole thing falls apart.

Epstein: Even when you demonstrate improvement in outcomes, practitioners are slow to adopt the changes. Sai [Parthasarathy], you said that when you compared yourself to some of your colleagues you hoped you were doing a better job, but you have no data to show that you are. Until we show this is actually clinically important, it's going to be very difficult to get people to change. I would suggest we need to do that first, before we spend millions of dollars to change the process.

Sassoon: Regarding automation, maybe, as we were saying yesterday, nobody knows what the static compliance is.

Parthasarathy: I think that's always the down side, and we see surgeons lamenting about how my friend is now a unique surgeon who does robotic surgery and the rest of the group can't, so they call upon him to do these prostate surgeries, but then they're also worried about what those guys will do if there's malfunction. So this is a philosophical question, because we need a good approach and a long-term plan: not something that we just sit around and wait for, hoping that it happens. It needs to be methodically thought about, and I think when you, Scott [Epstein], say that there are no data about how we measure these things and look at these tracings, measure the compliance, and whether what we do will have a tangible difference in outcomes. We have a situation of equipoise; we really don't know that intervention can actually help improve lives, which would allow the institutional review board to approve such a study. What else do we need to develop something? There's an opportunity there for research.

Hess: I think that a smart system has to look at a lot more than the ventilator, because the ventilator may not be the problem. The problem may be with the patient, so a smart system that I would envision would look at things like: What is the patient's $\mathrm{pH}$ ? What is the patient's $\mathrm{P}_{\mathrm{CO}_{2}}$ ? Maybe the problem with asynchrony is not what's set on the ventilator; maybe it's a problem with the patient and it should prompt the user that this patient has metabolic acidosis that needs to be ad- dressed. That's not a matter of just tweaking something on the ventilator.

Pierson: That gets back to the way I phrased my question initially. Is it just an incredibly complicated system and it's just a matter of time before we've figured out how to do the cloud computing or whatever needs to be done to figure it all out and make it work-or is there something inherently different?

Hess: I think it's incredibly complicated and just looking at the ventilator and signals is not going to be the answer.

Younes: I think how complicated it is depends on your target. If you want to have a comprehensive system to manage the patient, that would obviously be extremely complicated, but if you focus on a specific issue like improving synchrony, then that is a manageable problem: it's not very complicated. I'd say we should have an open mind about automation. Taking the position that technology is bad because an RT or doctor knows best is not a good idea. You point out that patients are highly variable, but if you take some COPD patients with the same numbers and ask 5 RTs or 5 doctors how to manage them, they would all treat them in different ways. Now, who's right? There's always going to be errors. It's a question of who makes the errors: an automated system or an individual? We should accept that we should try an automated system but that the decision should be based on outcomes, along with human intervention.

This article is approved for Continuing Respiratory Care Education credit. For information and to obtain your CRCE

(free to AARC members) visit

RCJournal.com

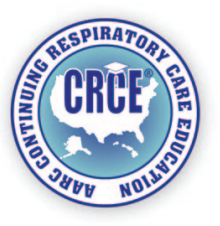

